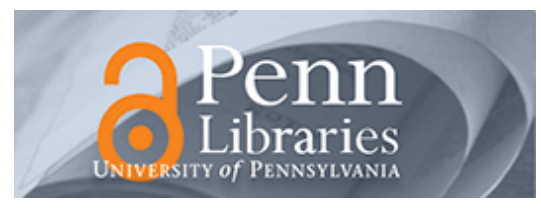

University of Pennsylvania

ScholarlyCommons

Operations, Information and Decisions Papers

Wharton Faculty Research

4-2007

\title{
Theories of Commitment, Altruism and Reciprocity: Evidence From Linear Public Goods Games
}

Rachel Croson

University of Pennsylvania

Follow this and additional works at: https://repository.upenn.edu/oid_papers

Part of the Other Economics Commons, Other Sociology Commons, and the Theory, Knowledge and Science Commons

\section{Recommended Citation}

Croson, R. (2007). Theories of Commitment, Altruism and Reciprocity: Evidence From Linear Public Goods Games. Economic Inquiry, 45 (2), 199-216. http://dx.doi.org/10.1111/j.1465-7295.2006.00006.x

This paper is posted at ScholarlyCommons. https://repository.upenn.edu/oid_papers/60

For more information, please contact repository@pobox.upenn.edu. 


\title{
Theories of Commitment, Altruism and Reciprocity: Evidence From Linear Public Goods Games
}

\begin{abstract}
Theories of commitment, altruism, and reciprocity have been invoked to explain and describe behavior in public goods and social dilemma situations. Commitment has been used to explain behaviors like water conservation and voting. Altruism has been applied to explain contributions to charities and intergenerational transfers and bequests. Reciprocity has been invoked to explain gift exchange and labor market decisions. This paper describes a set of experiments, which distinguish between these competing theories by testing their comparative statics predictions in a linear public goods setting. Results provide strong support for reciprocity theories over either theories of commitment or of altruism.
\end{abstract}

Disciplines

Other Economics | Other Sociology | Theory, Knowledge and Science 


\title{
Theories of Commitment, Altruism and Reciprocity: Evidence from Linear Public Goods Games
}

\author{
Rachel T.A. Croson \\ CrosonR@opim.wharton.upenn.edu \\ April, 1998
}

\begin{abstract}
Theories of commitment, altruism and reciprocity have all been invoked to explain and describe observed behavior in public goods and social dilemma situations. In particular, commitment theories have been used to explain behaviors like water conservation and voting. Theories of altruism are applied in explanation of contributions to charities and intergenerational transfers and bequests. And theories of reciprocity have been invoked to explain gift exchange and labor market decisions. This paper describes a set of experiments which distinguish between these competing theories by testing their comparative statics predictions in a linear public goods setting. Results provide strong support for reciprocity theories over either theories of commitment or of altruism.

Keywords: Reciprocity, Altruism, Experimental economics, Public goods, Charitable contributions

JEL Classification Codes: C9, D64, H41, C72
\end{abstract}

\footnotetext{
*The author thanks Jon Baron, Yan Chan, Robyn Dawes, Jerry Green, Elizabeth Hoffman, Mark Isaac, Eric Maskin, Sara Solnick, Lise Vesterlund, George Wu, participants at the Economic Science Association Fall Meetings as well as seminar participants at the University of Pennsylvania and the University of Iowa for helpful comments. All omissions or mistakes are the responsibility of the author. Funding of experiments from the Economic Science Lab at the University of Arizona is gratefully acknowledged.
} 


\section{Introduction}

US individuals made over 100 billion dollars of philanthropic contributions in 1995 (Giving USA, 1996). This behavior is inconsistent with traditional utility theory in which individuals care only for their own consumption. A number of alternative theories have been invoked to explain such philanthropic behavior in this and other settings. This paper describes a set of experiments which distinguish between three competing theories: commitment, altruism and reciprocity, by testing their comparative statics predictions in a linear public goods setting.

In commitment theories, individuals choose the actions they would most prefer everyone would choose (Laffont, 1975; Harsanyi, 1980). Thus they choose the action which maximizes their private payoff assuming that everyone else chooses the same action they do. Commitment theories are consistent with observed philanthropic behavior, voluntary cooperation in social dilemmas like water conservation (Laffont, 1975), tax evasion (Baldry, 1987), and voting (Struthers and Young, 1989) as well as voluntary contributions to public goods.

In altruism theories, the consumption of others appears positively as an argument in an individual's utility function (Becker, 1974; Andreoni, 1989, 1990). Models of altruism are also consistent with observed philanthropic behavior and have been used to explain intergenerational bequests (Becker, 1974), social security and other welfare systems (Coate, 1995), and helping behavior in the workplace (Rotemberg, 1994) as well as voluntary contributions to public goods.

In contrast, Sugden (1984) proposes a theory in which the principle of reciprocity acts as a constraint on traditional individual utility maximization. The principle says (roughly) 
that an individual may not free, cheap or easy ride when others are contributing. Models of reciprocity are also consistent with observed philanthropic behavior (when others are contributing) and have been used to explain individual behavior in tax evasion (Bordignon, 1993), helping in the workplace (Frey, 1993) and labor markets (Akerlof, 1982, 1984; Fehr and Gachter, forthcoming) as well as voluntary contributions to public goods.

This paper presents four separate experiments designed to distinguish between these theories by comparing their comparative statics predictions. The results of the first experiment (presented in section 4) demonstrate a significant and positive relationship between an individual's own contribution and his beliefs of the contributions of others in his group, consistent with theories of reciprocity and inconsistent with traditional self-interested theories or theories of commitment or altruism. The second and third experiments (presented in section 5) test the robustness of the first experiment by comparing an individual's own contributions and the actual contributions of others in his group in different settings. Similar results are generated. The final experiment (presented in section 6) further investigates the specific type of reciprocity our subjects demonstrate. We find evidence for middle reciprocity, where players try to match the middle (or average) contribution of the rest of his group, rather than the minimum or maximum.

This paper is organized as follows. Section 2 briefly describes the public goods production function and the voluntary contribution mechanism used in this experiment. Section 3 outlines the three classes of theories and their implications. In section 4 we present the experiment and results designed to distinguish between the competing theories. Section 5 describes two additional experiments designed to test for the robustness of our results. Section 6 describes another experiment which investigates individual behavior in more detail. 
Finally, section 7 concludes.

\section{Pure Public Goods and the Voluntary Contribution Mechanism}

Pure public goods are goods that are both nonrival and nonexcludable. The experiments described in this paper use a linear and pure public good to distinguish between our competing hypotheses. The mechanism used to fund the public good is the voluntary contribution mechanism which most closely parallels philanthropic giving or contributing behavior. This mechanism has been examined extensively in previous literature (see Davis and Holt, 1994, chapter 6 and Ledyard, 1995 for complete reviews).

\section{A. The Mechanism}

The mechanism is structured as follows. Assume each player $i$ in a group of $\mathrm{N}$ identical players has some endowment $E_{i}$ which can either be contributed to a group account and used to produce units of a public good or can be privately consumed. Call the amount contributed to the group account by $i$, $\mathrm{x}$. The individual's earnings from private consumption is simply the amount consumed $\left(\mathrm{E}_{\mathrm{i}}-\mathrm{x}_{\mathrm{i}}\right)$. The individual's earnings from contributions to the group account is a multiple of the sum of contributions by all participants in the group $\mathrm{P}\left(\sum_{\mathrm{inN}} \mathrm{X}_{\mathrm{i}}\right)$.

There is a pure public goods problem whenever $<\mathrm{P}<1$. When $\mathrm{P}<1$, contributing to the public good is never optimal for the self-interested individual. Contributing one unit to the public good earns him only $\mathrm{P}$, and costs him 1 . When $<\mathrm{P}$, contributing to the public good is always optimal for the group as a whole. Contributing one unit to the public good costs an individual 1, but earns NP for the group.

This mechanism of contributions to the public good in this game is purely voluntary, similar to the institution of charitable contributions. 


\section{B. Related Experiments}

Marwell and Ames (1979, 1980, 1981) were the first to test public goods provision behavior in a linear and pure public good using the voluntary contribution mechanism. They find that when subjects play a one-shot, context-free public goods game they contribute around half their endowment to the public good and consume the rest.

Later research suggests that when subjects play a the same public goods game finitely repeated (with a subgame-perfect equilibrium of full free riding), contributions in the first period are similar to those observed in Marwell and Ames, but decrease over time toward the free-riding solution (Davis and Holt, 1994; Ledyard, 1995). Although contributions reach their lowest point in the last period of the game, they do not quite reach the equilibrium outcome of full free riding.

In the first of our experiments, we elicit subjects' beliefs about the contributions of their group and compare those beliefs with their contributing behavior. Some previous experiments have attempted to investigate the relationship between an individual's belief and their actions in public goods settings. However, most have deceived subjects about the true contributions of the other players (e.g. Messick et al., 1983; Schroeder et al., 1983; Poppe and Utens, 1986; Fleishman, 1988; Weimann, 1994). There is also a large literature in psychology on belief elicitation and manipulation in prisoners' dilemma games.

In contrast to most of this previous literature, in the experiment presented in this paper, no deception is used. Instead, players' beliefs of other players' behavior are elicited and compared with the players' own contributions.

\section{Three Theories and Hypotheses}


In this section we present three types of theories which have been used to explain economic behavior in various settings (including the voluntary provision of public goods) and between which we would like to discriminate; commitment, altruism and reciprocity. In particular, we describe the development of each, point to settings in which it has been used and describe the comparative statics hypotheses which we will test.

In addition to these theories, however, we would like to retain the traditional hypothesis of pure self-interest as a benchmark. This hypothesis posits a utility function in which players are concerned only about their own earnings. In the notation above we have

$\mathrm{U}_{\mathrm{i}}=\left(\mathrm{E}_{\mathrm{i}}-\mathrm{X}_{\mathrm{i}}\right)+\mathrm{P} \Sigma_{\mathrm{i}} \mathrm{X}_{\mathrm{i}}$

Whenever $<\mathrm{P}<1$, then the optimal contribution $\mathrm{xi}^{*}=0$, and thus $\delta \mathrm{x}_{\mathrm{i}} * / \delta \mathrm{x}_{\mathrm{j}}=0 \mathrm{j} \neq \mathrm{iN}$.

When individuals care only about their own payoffs, a pure public goods problem like the one our subjects face generates a unique equilibrium in which all players fully free ride (contribute zero). In this free riding equilibrium, an individual's contribution is independent of what others in the group contribute. Thus our benchmark free riding hypothesis is that (1) subjects will always contribute zero to the public good and (2) (the comparative static prediction) there will be no correlation between what an individual contributes and what others in his group contribute.

\section{A. Commitment Theories}

Theories of this kind typically rely on Kantian reasoning on the part of individuals. These theories then go on to generate behavior which involves (1) positive levels of contributions to public goods but also (2) contributions which do not change as the contributions of others changes. Collard $(1978,1983)$ calls these "Kantian" theories and 
Sugden (1984) refers to the principle underlying this behavior as the "principle of unconditional commitment.”

Laffont (1975) analyzes the case where individuals believe that others will act as they do, then maximize their utility given that belief. Under these beliefs, he shows that individuals voluntarily contribute nonzero amounts toward public goods and social welfare increases. Similarly, Harsanyi (1980) describes the principle of "rational commitment" in which an individual takes the action "which will maximize social utility if it is followed by everybody in this kind of situation.” (p. 116). For our purposes, this implies that individuals simply contribute the level she would most prefer that every member of the group would contribute (independent of her beliefs). If everyone behaves according to this principle, the argument goes, public goods are funded and social welfare increases.

Commitment theories have been used to describe behavior in water conservation (Laffont, 1975), lack of littering (Laffont, 1975), tax evasion (Baldry, 1987), voting (Struthers and Young, 1989), and other voluntary public goods provision (Bordignon, 1990).

Some evidence for these types of norms has been observed in experimental settings. For example, Baron and Spranca (1997) demonstrate the existence of "protected values." In their experiments they identified actions (e.g. free riding) which subjects would simply not do, regardless of the (hypothetical) personal gain, or the actions of other subjects. Baldry (1987) and Bosco and Mittone (1997) experimentally examine tax evasion, and report a large role played by moral constraints in individuals' behavior.

Commitment theories imply that an individual maximizes the utility function $U_{i}=\left(E_{i}-X_{i}\right)+P \Sigma_{i} X_{i}$ subject to his belief that $\quad x_{i}=x_{j} j \neq i N$ 
Integrating the constraint into the objective function yields

$\mathrm{U}_{\mathrm{i}}=\left(\mathrm{E}_{\mathrm{i}}-\mathrm{x}_{\mathrm{i}}\right)+\mathrm{PNx}_{\mathrm{i}}$

Whenever $<\mathrm{P}<1$, then the optimal contribution $\mathrm{x}_{\mathrm{i}}^{*}>0$, and thus $\delta \mathrm{x}_{\mathrm{i}} * / \delta \mathrm{x}_{\mathrm{j}}=0 \mathrm{j} \neq \mathrm{iN}$.

So commitment theories have two important implications which we can test in a public goods setting, yielding the commitment hypothesis. First, they predict strictly positive (but constant) levels of contribution. Second, (the comparative static prediction) they predict a zero correlation between one's contributions and the contributions of others. In particular, under commitment theories each individual chooses the level of contributions which they prefer everyone would choose. As the actual contribution level of others changes, one's own contribution remains stable. Notice, this is the same comparative static prediction as generated by the benchmark theory of self-interest above. Later in our statistical analyses we will look to the absolute level of contributions to distinguish these theories.

\section{B. Altruism Theories}

A second set of theories of altruism assume that individuals care directly about the consumption or utility of others. These theories then go on to generate behavior which involves (1) positive levels of contributions to public goods, but also (2) contributions which are negatively related to the contributions of others.

In Becker (1974) for example, an individual's utility is defined over not only his own consumption, but also the consumption of others (positively in the case of altruism). Collard (1978) distinguishes between this type of altruism, which he calls commodity-related, and altruism in which an individual's utility is defined over his level of consumption and the utility of others (positively in the case of altruism), which he calls utility-related. 
Models of altruism have been influential in explaining economic behavior in many settings, including charitable contributions and volunteer behavior (e.g. Unger, 1991; Smith, Kehoe and Cremer, 1995), social security and other welfare systems (e.g. Coate, 1995), intergenerational bequests and macroeconomic growth (e.g. Rangazas, 1991; Hori, 1992; Chakrabarti, Lord and Rangazas, 1993; Strawcyznski, 1994), fertility (e.g. Becker and Barro, 1988; Tamura, 1994), migration (e.g. Tcha, 1995), safety decisions (Jones-Lee, 1992), rent-seeking (Jones, 1996) and behavior in the workplace (e.g. Rotemberg, 1994). Other studies have examined altruism from an evolutionary perspective, either describing evolutionary reasons for altruistic preferences or determining the evolutionary outcomes of societies with heterogenously altruistic individuals (e.g. Bergstrom and Stark, 1993; Haltiwanger and Waldman, 1993; Samuelson, 1993; Bergstrom, 1995).

However, recently a number of papers have presented theoretical results which challenge theories of altruism (Warr, 1982; Warr, 1983; Roberts 1984; Sugden, 1985; Bergstrom et al., 1986; Andreoni 1988a; Bernheim and Stark, 1988) as well as empirical data inconsistent with these models. For example, models of pure altruism imply full "crowding out" of both voluntary contributions and subsidies (Warr, 1982; Roberts, 1984; Bernheim, 1986; Andreoni, 1988a), although there is little evidence of crowding out empirically (Abrams and Schitz, 1978; 1984; Clotfelter, 1985) or experimentally (Andreoni, 1993). Models of altruism explaining bequests and inter-vivos transfers have similarly found little support in the data (e.g. Cox, 1987; Altonji, Hayashi and Kotlikoff, 1992; Cox and Rank 1992; Hayashi, 1995; Laitner and Juster, 1996; Wilhelm, 1996) as have models for charitable giving (e.g. Khanna, Posnett and Sandler, 1995).

Andreoni $(1989,1990)$ generalized previous models of altruism to incorporate into an 
individual's utility function not only the consumption (or welfare) of others, but also the "warm glow" of giving (a related paper, Abel and Warshawsky, 1988, discusses the "joy of giving" and another, Feldstein, 1975 models a similar process.). Under this model of impure altruism, an individual cares not only about the consumption of others, but also receives some private goods benefit from their gift per se. Andreoni (1990) shows that impure altruism implies only partial crowding out, consistent with the empirical results. Models of impure altruism have been used to explain behavior in the supply of charity services by hospitals (Frank and Salkever, 1991) and contributions to public goods and charities in general (Andreoni, 1989, 1990).

A number of experiments have tested for the existence and malleability of (pure or impure) altruistic preferences. Probably the best-known are experiments in the dictator game (where one individual is given a sum of money to allocate in any way they wish between themselves and another; Camerer and Thaler, 1995 present a review of such experiments). Subjects frequently allocate positive amounts to the other player in the game (Forsythe et al., 1994; Hoffman et al., 1994), and the amounts allocated change with the social distance between the players (Hoffman, McCabe and Smith, 1996), the perception of neediness of the recipient (Eckel and Grossman, 1996b) and other institutional factors. Altruism has also been used to explain experimental behavior in prisoners dilemma games (Andreoni and Miller, 1993; Cooper et al., 1996), public goods games (Palfrey and Rosenthal, 1988; Andreoni, 1995), and bargaining (Forsythe, Kennan and Sopher, 1991).

For purposes of our study, we will test the comparative static predictions of models of pure and impure altruism. Under pure altruism, individuals maximize a utility function which includes both their own private consumption and the consumption generated to the group from 
the public good as below

$\mathrm{U}_{\mathrm{i}}=\mathrm{Ui}_{\mathrm{i}}\left(\left[\left\{\mathrm{E}_{\mathrm{i}}-\mathrm{X}_{\mathrm{i}}\right\}+\mathrm{P} \sum_{\mathrm{i}} \mathrm{X}_{\mathrm{i}}\right], \mathrm{PN} \Sigma_{\mathrm{i} \mathrm{Xi}_{\mathrm{i}}}\right)$

where $\mathrm{U}_{\mathrm{i} 1}>0, \mathrm{U}_{\mathrm{i} 11}<0 ; \mathrm{U}_{\mathrm{i} 2}>0, \mathrm{U}_{\mathrm{i} 22}<0$ (both personal consumption and altruistic consumption are normal goods with decreasing returns)

Whenever $<\mathrm{P}<1$, then the optimal contribution $\mathrm{x}_{i}^{*}>0$. However, under this assumption $\delta \mathrm{x}_{\mathrm{i}} * / \delta \mathrm{x}_{\mathrm{j}}<0 \mathrm{j} \neq \mathrm{iN}$. This result is akin to crowding out (see Sugden, 1982, p. 346 for a proof). Under impure altruism, individuals maximize a utility function which includes the above as well as the amount they contributed to the public good, as below.

$\mathrm{U}_{\mathrm{i}}=\mathrm{U}_{\mathrm{i}}\left(\left[\left\{\mathrm{E}_{\mathrm{i}}-\mathrm{X}_{\mathrm{i}}\right\}+\mathrm{P} \sum_{\mathrm{i}} \mathrm{x}_{\mathrm{i}}\right], \mathrm{PN} \Sigma_{\mathrm{i}} \mathrm{X}_{\mathrm{i}}, \mathrm{x}_{\mathrm{i}}\right)$

where $\mathrm{U}_{\mathrm{i} 1}>0, \mathrm{U}_{\mathrm{i} 11}<0 ; \mathrm{U}_{\mathrm{i} 2}>0, \mathrm{U}_{\mathrm{i} 22}<0 ; \mathrm{U}_{\mathrm{i} 3}>0, \mathrm{U}_{\mathrm{i} 33}<0$ (personal consumption, altruistic consumption and warm glow consumption are normal goods with decreasing returns)

Again, whenever $<\mathrm{P}<1$, then the optimal contribution $\mathrm{xi}^{*}>0$. Also under this assumption, $\delta \mathrm{x}_{\mathrm{i}} * / \delta \mathrm{x}_{\mathrm{j}}<0 \mathrm{j} \neq \mathrm{iN}$. This result is akin to partial crowding out; an increase in the amount of the public good provided implies a decrease in an individual's own contribution, although the decrease is smaller than under pure altruism (see Andreoni, 1989, p. 1451 for a proof). Thus our comparative static prediction from both types of theories of altruism (the altruism hypothesis) is that there will be a negative relationship between an individual's own contribution and (his beliefs about) the contributions of others in his group.

\section{Reciprocity Theories}

A final set of theories of reciprocity assume that individuals reciprocate or match the contributions of others. These theories then go on to generate behavior which involves (1) 
positive levels of contributions to public goods, but also (2) contributions which are positively related to the contributions of others.

Sugden (1984) describes a model in which individuals profit-maximize subject to an external constraint; the principle of reciprocity. This principle says that an individual must contribute the minimum of (1) the least any other member of his group is contributing and (2) the level of contribution he would most prefer that every member of the group make (the same as the level of contributions he would make under commitment theories). By assuming this principle as a constraint on behavior, Sugden derives the existence of (multiple) equilibria in settings of both identical and nonidentical players.

Reciprocal reasoning has been used to explain empirically observed individual behavior in tax evasion (Bordignon, 1993), gift exchange (Solow, 1994; Kranton, 1996), public goods provision (Hollander, 1990), helping in the workplace (Frey, 1993), joint ventures (Kogut, 1989), and labor markets (Akerlof, 1982, 1984; Fehr and Gachter, forthcoming).

A number of experiments have reported behavior consistent with reciprocity as well. In experimental labor markets, subjects playing the role of firms offer efficiency wages and subjects playing the role of workers respond reciprocally by offering more effort than is individually rational (Fehr, Kirchsteiger and Riedl, 1996; Fehr and Tougareva, 1996; Fehr and Tyran, 1996; Kirchler, Fehr and Evans, 1996; Fehr, Gachter and Kirchsteiger, 1997; Gachter and Falk, 1997; Fehr, Kirchsteiger and Riedl, 1998). A similar result was found in experimental goods markets (Fehr, Kirchsteiger and Riedl, 1993). Reciprocal behavior was also found in experimental bargaining games like the trust game (Berg, Dickhaut and McCabe, 1995; Van Huyck, Battalio and Walters, 1995; Jacobsen and Sadreih, 1996; Abbink, Irlenbusch and Renner, 1997; Guth, Ockenfels and Wendel, 1997; Buchan, Johnson and Croson, 1998) 
and the common pool resource public goods game (Messick et al., 1983; Schroeder et al., 1983; Poppe and Utens, 1986; Wade-Benzoni, Tenbrunsel and Bazerman, 1996). Other bargaining-type experimental games have also exhibited evidence of reciprocity (Bolton, Brandts and Katok, 1996; Bolton, Brandts and Ockenfels, 1997).

For purposes of our study, we will test the comparative static predictions of models of reciprocity, which predict a significant positive relationship between an individual's contributions to the public good and those of his group. In our notation, under this theory an individual maximizes his personal utility as below

$\mathrm{U}_{\mathrm{i}}=\left(\mathrm{E}_{\mathrm{i}}-\mathrm{X}_{\mathrm{i}}\right)+\mathrm{P} \sum_{\mathrm{i}} \mathrm{X}_{\mathrm{i}}$

subject to $\quad x_{i} \geq \min \left(x_{i}{ }^{c}, x_{j} j N\right)$

where $\mathrm{xi}^{\mathrm{c}}$ is the optimal level of contribution under commitment theories

Whenever $<\mathrm{P}<1$, then the optimal contribution $\mathrm{xi}^{*}>0$. However, under this assumption in equilibria it can be that $\delta x_{i} * / \delta x_{j}>0 j \neq i N$. See Result 4 (p. 780) of Sugden (1984) for a proof. This theory is thus consistent with a positive correlation between one's own contribution and the contribution of other members of the group; this prediction will be our reciprocity hypothesis.

It is worth noting that Sugden's model of reciprocity is a model of simultaneous (not sequential) matching of contributions. Players in this game do not wait to see what others have contributed, and then reciprocate their contributions. Instead, everyone makes contributions at the same time, maximizing their self-interest subject to the principle of reciprocity and given their beliefs of others' contributions. Thus our test of this theory of reciprocity will (of necessity) be a simultaneous one. 


\section{Summary}

The experiments reported in this paper allow us to discriminate between the comparative statics of three classes of theories of behavior, all of which have been invoked to explain the voluntary provision of public goods. The first class of theories (commitment rules) predicts no correlation between an individual's contribution and the contributions of others, or his beliefs about them (a similar zero correlation is predicted by traditional theories of full free riding). The second class of theories (pure and impure altruism) predicts a negative correlation. Finally the third class of theories (reciprocity) predicts a positive correlation.

It should be noted that all these models are models of one-shot behavior. In experiments, however, subjects seldom play equilibria on their first try. Rather, they adjust their behavior and converge toward equilibria. In order to give these equilibria their best chance, the experimental design involves two 10-fold repetitions of a public goods game (consistent with previous experiments, Davis and Holt, 1994; Ledyard, 1995). Since the equilibria described above are equilibria of the stage game, they are also equilibria of the finitely repeated game (Smith, 1990).

Sections 4, 5 and 6 below present the experiments which distinguish between these different theories.

\section{Study I: Comparing Contributions with Estimated Contributions of Others}

This study tests the comparative static predictions of models of commitment, altruism and reciprocity by comparing an individual's contribution with his belief about the contribution of others. Subjects play a finitely repeated linear public goods game. Before each period, they are asked to estimate the contributions of the other members of their group. The first 
subsection describes the experimental design and parameters, the second discusses results investigating the comparative statics of behavior and the third addresses the accuracy of subjects' beliefs. The fourth subsection concludes.

\section{A. Experimental Design and Parameters}

This experiment was designed to replicate previous experiments in finitely repeated linear public goods games as closely as possible (Davis and Holt, 1994; Ledyard, 1995). The same structure of game and parameter values as in previous experiments were used.

In each period of the game, each subject was endowed with 25 tokens which could be allocated either to a private account, which paid $2 \notin$ per token to the individual only, or to a group account (the public good), which paid $1 \varnothing$ per token to each of the four members of the individual's group. Notice that each period of this experiment incorporates a pure public goods problem. Under traditional assumptions of self-interest, regardless of the decisions of the other players, each individual strictly prefers to place all of his tokens in his private account, earning $2 \varnothing$ per token, than in the group account, earning $1 \varnothing$ per token. However the group as a whole earns $4 \phi$ when a token is placed in the group account $(1 \phi$ to each of the four members) but only earns $2 \varnothing$ when the token is placed in a private account. This yields an MPCR of .5, similar to that in previous papers (Davis and Holt, 1994; Ledyard, 1995).

In a departure from previous experiments, each period of the game was divided into two stages; the "guessing" and the "decision" stage. In the guessing stage, subjects estimated the total number of tokens the other three members of their group would contribute to the group account in the upcoming decision stage. They were compensated for accurate estimates. In the decision stage, subjects made their personal and private contribution decisions, as in previous experiments. 
At the end of each period, subjects were reminded of their own estimate, told the true aggregate contribution of the other three members of group, the total group contribution and their earnings from both the estimation stage and the contribution stage.

Subjects played two identical ten-period linear public goods games. Subjects played the first game, and then were told there was enough time to play a second (as in Andreoni, 1988b). The second game was always identical to the first.

Twenty-four subjects arranged in six groups of four participated in this experiment. Subjects were undergraduate students at the University of Arizona summer session. They were paid a five dollar show-up fee along with their earnings in the experiment. Average earnings were $\$ 14.69$, plus the $\$ 5$ fee, for less than an hour of experimental time. The entire experiment was computerized; instructions were given through the computer screen, subjects entered their contributions via the keyboard and, at the end of each period, feedback about the outcome was displayed on the screen. Subjects could also access a "history" of past outcomes of their group at any time.

In the following subsections we directly test the comparative statics of commitment, altruism and reciprocity theories by investigating the relationship between an individual's beliefs of what others will contribute and his own contributions. Commitment theories predict a zero correlation, altruism theories a negative correlation and reciprocity theories a positive correlation.

\section{B. Results: Testing Comparative Statics}

1. Overall

A random effects regression as below compares an individual's contribution with his belief of what the rest of his group will contribute. 
$\mathrm{CONT}_{\mathrm{it}}=\alpha_{0}+\alpha_{1} \mathrm{GUESS}_{\mathrm{t}}+\alpha_{2}$ PERIOD $+\sum_{\mathrm{i} \neq 1} \beta_{\mathrm{i}} \mathrm{IND}+\varepsilon_{\mathrm{i}}$

The dependent variable is an individual i's contribution to the public good in period t. Independent variables are the individual's GUESS of what the other three members of his group will contribute in this same period t, the PERIOD number, and an indicator variable for each individual (IND). A random effects regression not only allows for individual-specific intercepts (from the indicator variables) but also individual-specific error terms. For a complete discussion of random effects regression see Greene, 1990. Results of the regression are reported in Table 1, parameter estimates for individual dummies are suppressed for ease of presentation.

\section{Insert Table 1 about here}

This regression reports a significant positive relationship between a subject's guess of what the other three members of his group will contribute and his own contribution. This result strongly supports reciprocity theories over theories of commitment (which predicted a zero correlation) and altruism (which predicted a negative correlation).

The intercept in this regression was also positive, consistent with previous experimental results that subjects make positive contributions in similar games (Davis and Holt, 1994; Ledyard, 1995). The coefficient on period is not significant.

Identical regressions using only the data from the first game (the first 10 periods) or the second game (the second 10 periods) yield similar results, reported in Table 2.

Insert Table 2 about here 
The intercept and GUESS coefficient is similarly positive and significant in each individual game. The PERIOD coefficient is significantly negative in the first game, suggesting declining contributions over time, also observed in previous experiments, (Davis and Holt, 1994; Ledyard, 1995). However, by the second game contributions appear to have stabilized and no decrease is observed.

While these analyses examine the correlation between contributions and beliefs over time, alternatively, we can investigate the between-subject correlation between contributions and beliefs in only the first or only the last periods of the game. To do this, we estimate the following random effects OLS regression

$\mathrm{CONT}_{\mathrm{it}}=\alpha_{0}+\alpha_{1} \mathrm{GUESS}_{\mathrm{t}}+\sum_{\mathrm{i} \neq 1} \beta_{\mathrm{i}} \mathrm{IND}+\varepsilon_{\mathrm{i}}$

separately for only period 1 and only period 10 . Table 3 provides results from these regressions.

Insert Table 3 about here

Again, consistent with the reciprocity model, we find a significantly positive relationship between an individual's contributions and his estimates of others' contributions. In addition, we observe positive (but highly variable) contributions in period 1 of the game, and significantly lower contributions in period 10 of the games, consistent with previous experiments in this area which document decreasing contributions over time (Davis and Holt, 1994; Ledyard, 1995).

\section{Individual Characterizations}

A second type of analysis characterizes the behavior of individual subjects in the 
experiment. For each of the 24 subjects, we calculate the correlation between their contribution and their belief of the contribution of others in their group. In this way, we can identify individual subjects whose behavior is consistent with comparative statics of commitment, altruism or reciprocity models. Table 4 depicts the results from this analysis.

Insert Table 4 about here

Twenty-two out of 24 subjects (almost 92\%) exhibit a positive correlation between their own contribution and their estimates of the contributions of others, consistent with models of reciprocity. Only two subjects exhibit a negative correlation, consistent with models of altruism, and none a zero correlation, consistent with models of commitment.

These results represent a statistically significant difference from random behavior. A chi-squared test comparing the actual categorization of subjects against a null hypothesis of equal probability of all three types, rejects the null at $\mathrm{p}<.01$.

\section{Results: Estimate Accuracy}

In this experiment, each subject estimated what others in his group would contribute. One important question involves the accuracy of these estimates.

Figure 1 shows the average absolute estimation error made by each group in each period of the game. This error is calculated by computing the absolute error of each subject in each period (the distance between their guess and the other three subjects' actual contributions) and averaging within each group. If all subjects were extremely bad guessers this average absolute estimation error could be as high as 25 . Instead subjects appear to be fairly accurate in their estimations of others' behavior.

Insert Figure 1 about here 
We can define an individual subject's estimation error as the difference between that subject's estimate and the actual contributions of the other members of his group. Over all ten rounds of the first game, only eight out of 24 subjects exhibited any significantly positive levels of error (overoptimism). In the second game, no subjects exhibited significant levels of error. Throughout the experiment, most subjects provided unbiased guesses of what their counterparts in the public goods game will do.

\section{Conclusion}

This study was designed to provide data which could distinguish between models of commitment, altruism and reciprocity by comparing their comparative static predictions. In particular, we compare an individual's contribution in a public goods game with his beliefs about the contributions of others. Results from a random effects regression demonstrate a significant positive relationship, consistent with models of reciprocity and inconsistent with models of commitment or altruism. In addition, an analysis at the level of individual subject is run. Almost $92 \%$ of the subjects (22 out of 24 ) demonstrate a positive correlation between their own contributions and their beliefs of others contributions, consistent with reciprocity models. The remaining $8 \%$ exhibit a negative correlation, consistent with models of altruism and none exhibit a zero correlation, consistent with models of commitment and of traditional self-interest models.

In addition, we provide an analysis of the accuracy of subjects' beliefs in this setting. We find that subjects' beliefs are quite accurate. In the first game, only eight subjects out of 24 had significantly positive levels of error; in the second game no subjects did.

Although these results appear encouraging for reciprocity models, a few questions 
remain. First, it may be that asking subjects for their estimates of others' actions leads them to think reciprocally where they wouldn't otherwise (an elicitation hypothesis). Second, it may be that the repeated game nature of this experiment is yielding the positive correlation and not reciprocity per se (a reputation hypothesis).

To answer these questions and test the robustness of our results, two more experiments were run and the comparative static predictions of our models re-analyzed. Neither of the experiments involved the elicitation of beliefs of others' actions. Instead, we compare an individual's contribution with the actual contribution of the other members of his group. Since in this experiment, subjects' elicited beliefs were quite accurate, we claim the comparative static predictions from the models will transfer to this new context. The next section describes the new experiments and their results.

\section{Study II: Comparing Contributions with Actual Contributions of Others}

\section{A.. Testing the Elicitation Hypothesis}

Our first question involves the extent to which asking subjects to estimate the contributions of others leads them to play reciprocally where they wouldn't otherwise. To test this hypothesis, we ran a new experiment, identical to the first but excluding the estimation stage. Twenty-four subjects, different from the previous subjects but from the same subject pool, participated in this experiment, arranged in six groups of four. Average earnings for this experiment were $\$ 13.91$ (plus the $\$ 5$ show-up fee) for less than one hour of experimental time.

Here, we are interested in the correlation between subjects' contribution and the ACTUAL total contribution of others in this same period (unfortunately, we can't compare an 
individual's contribution with his belief about the contributions of others when those beliefs are not elicited). A zero correlation is predicted by commitment theories, a negative correlation by altruism theories and a positive correlation by reciprocity theories. With this data, we estimate the random effects OLS regression

$\mathrm{CONT}_{\mathrm{it}}=\alpha_{0}+\alpha_{1} \mathrm{ACTUAL}_{\mathrm{t}}+\alpha_{2} \mathrm{PERIOD}+\sum_{\mathrm{i} \neq 1} \beta_{\mathrm{i}} \mathrm{IND}+\varepsilon_{\mathrm{i}}$

for both the previous experiment and this one. Results from these regressions are reported in Table 5, below.

Insert Table 5 about here

Consistent with the reciprocity hypothesis, a significant positive relationship is found between an individual's contribution and the actual contribution of others in both the previous experiment (Guess) and this experiment (No Guess). First, focusing on the previous experiment, this relationship is a bit less strong than the relationship between an individual's contribution and estimate of others' contributions (where the coefficient was .202 rather than .164). The relationship appears somewhat weaker in this experiment (.077 versus .164), nonetheless it is still significant at the $1 \%$ level.

Interestingly, subjects contributed on average significantly less in the previous experiment (when they were asked to estimate the contributions of others) than in this one, as can be seen by the difference in intercept between the two regressions. This difference is explored in more detail in a related paper, Croson (1997). Finally, both regressions show a significant decrease in contributions over the course of the games, consistent with evidence from previous experiments (Davis and Holt, 1994; Ledyard, 1995). 
In a parallel to our first analysis, we can also compare within an individual, their correlation between their contributions and the actual contributions of others in their group. Table 6 provides those results for the previous experiment and this experiment.

\section{Insert Table 6 about here}

In the previous experiment (Guess), 21 out of 24 subjects $(87.5 \%)$ exhibited a positive correlation between their own contribution and the actual contributions of others in their group, consistent with reciprocity theories. Only 3 subjects exhibited a negative correlation, consistent with altruism theories and no subjects exhibited a zero correlation. The pattern in this experiment (No Guess) is similar, 19 out of 24 subject exhibited a positive correlation (79\%), only 5 a negative correlation and none exhibited a zero correlation. These results represent a statistically significant difference from random behavior. A chi-squared test comparing the actual categorization of subjects against a null hypothesis of equal probability of all three types, rejects the null at $\mathrm{p}<.01$, for each experiment independently as well as for both of them together.

While there are some differences in the level of contributions between games in which estimates of others' contributions are elicited and where they are not, results from this subsection demonstrate that the comparative statics of reciprocity theories remain most consistent with the data, even when beliefs are not elicited. This allows us to reject the elicitation hypothesis.

\section{B. Testing the Reputation Hypothesis}

A further concern is that the positive correlation observed is arising from some sort of reputation development rather than from reciprocity. In both our original experiment and the 
second experiment presented above, subjects were formed into groups which remained constant for the duration of the experiment. This matching procedure is by far the most common one used in previous experiments (Davis and Holt, 1994; Ledyard, 1995). However, in this setting it may be another cause of our results. For example, if all subjects were playing in a way consistent with Kreps et al. (1986), and all subjects believed all subjects were playing in this way, we might observe a positive correlation similar to the one we observed, but for reputational rather than reciprocal reasons. The experiment reported in this subsection was designed to test this alternative explanation.

A different 24 subjects participated in this experiment (Strangers). The experiment was run in two separate sessions of 12 subjects each. Subjects played the same game as in the previous experiments. After each period of the game, however, subjects were randomly reassigned to new groups of four (as in Andreoni, 1988b; Croson, 1996; van Winden and Keser, 1997). Thus it was extremely unlikely a subject would play with the same group of three other people more than once during the session. This type of matching scheme has been demonstrated to reduce reputation effects (for an explanation of why, see Andreoni, 1988b). Average earnings for this experiment were $\$ 11.83$ (plus the $\$ 5$ show-up fee) for less than one hour of experimental time.

Here, we are again interested in the correlation between subjects' contribution and the ACTUAL total contribution of others with whom he is matched in this same period. If the previously-observed positive correlation is being caused by reputational issues (the reputation hypothesis) we should observe a zero correlation in this experiment. Thus, with this data, we estimate the random effects regression

$\mathrm{CONT}_{\mathrm{it}}=\alpha_{0}+\alpha_{1} \mathrm{ACTUAL}_{\mathrm{t}}+\alpha_{2}$ PERIOD $+\sum_{\mathrm{i} \neq 1} \beta_{\mathrm{i}} \mathrm{IND}+\varepsilon \mathrm{i}$ 
for this experiment. Results from these regressions are reported in Table 7, below.

Insert Table 7 about here

Consistent with the reciprocity hypothesis, a significant positive relationship is found between an individual's contribution and the actual contribution of others in this experiment as well. Although the relationship appears somewhat weaker in this experiment than in previous ones (suggesting some reputation formation may be going on), nonetheless it is still significant at the $1 \%$ level, supporting theories of reciprocity over those of commitment or altruism.

In similar analysis to that above, we also compare, within an individual, the correlation between their contributions and the actual contributions of others in their group. Table 8 provides those results for this experiment.

Insert Table 8 about here

As in previous experiments, most of the subjects exhibited positive correlations between their own contributions and contributions of others, consistent with reciprocity theories (almost 71\%). Only three out of 24 subjects exhibited negative correlations, consistent with altruism theories. In contrast to previous experiments, however, four subjects exhibited zero correlations between their own contributions and the contributions of others. Closer inspection reveals that these correlations were generated by four subjects who fully free rode (contributed zero) throughout the entire experiment. This result of more free riding and lower contributions in strangers experiments than among stable groups is consistent with previous research (Croson, 1996; van Winden and Keser, 1997).

These results represent a statistically significant difference from random behavior. A 
chi-squared test comparing the actual categorization of subjects against a null hypothesis of equal probability of all three types, rejects the null at $\mathrm{p}<.01$.

While there are more free riders and lower contributions in this experiment than in previous ones, results are still supportive of the comparative statics of reciprocity theories over

those of commitment or altruism. A significant and positive relationship is found between an individual's contribution and the contribution of others in his group.

\section{Conclusion}

In this section we presented the results of two further experiments, which test the robustness of our previous result. The first demonstrates a positive relationship between an individual's contribution and the contributions of others even when beliefs are not elicited. The second demonstrates a similarly positive relationship even when reputational concerns are severely reduced. We conclude that reciprocal concerns in this setting are robust. Having demonstrated support for theories of reciprocity in three different settings, we now turn to Study III, which provides a characterization of the type of reciprocity individuals exhibit.

\section{Study III: Types of Reciprocity}

In Sugden's (1984) model of reciprocity, he suggests that actors will match the minimum contribution of others. In contrast, however, we can imagine different types of reciprocity in which subjects try to match the average contribution of others, or possibly even the maximum. The experiment reported in this study distinguishes between these different specifications of reciprocity.

\section{A. Experimental Design and Parameters}

Twenty-four subjects, distinct from previous participants but from the same subject 
pool, participated in this experiment. Subjects were arranged into groups of four and played two ten-round games retaining the same groups. All parameter values were the same as in the previous experiments, and no elicitation of beliefs was made.

In contrast to the previous experiments, however, after each period subjects were informed not only of the aggregate contribution of the other three members of their group, but also of the individual contributions of the other three members of the group (as in Sell and Wilson, 1991; Croson, forthcoming). Thus subjects could attempt to match either the maximum, the minimum or the middle contribution. As before, subjects took home their earnings from the experiment (average \$14.03) plus their $\$ 5$ show-up-fee.

\section{B. Results: Testing Comparative Statics}

In this experiment we again observe a positive relationship between an individual's own contribution and the actual contribution of others in their group. With this data, we again estimate the random effects OLS regression

$\mathrm{CONT}_{\mathrm{it}}=\alpha_{0}+\alpha_{1} \mathrm{ACTUAL}_{\mathrm{t}}+\alpha_{2} \mathrm{PERIOD}+\sum_{\mathrm{i} \neq 1} \beta_{\mathrm{i}} \mathrm{IND}+\varepsilon_{\mathrm{i}}$

Results from this regression are shown in Table 9, below.

Insert Table 9 about here

As before, we observe a significantly positive relationship between one's own contribution and the actual contributions of others in one's group. The intercept is significantly positive, and the period variable significantly negative, consistent with results from previous experiments (Davis and Holt, 1994; Ledyard, 1995).

A parallel analysis as above involving correlations at the individual level also yields 
similar results, as shown in Table 10.

\section{Insert Table 10 about here}

Almost $88 \%$ (21 subjects out of 24) exhibit a positive correlation, consistent with theories of reciprocity. Only two subjects out of 24 (8.33\%), exhibit a negative correlation, consistent with theories of altruism. One subject's behavior yields a zero correlation, closer inspection shows that subject contributes nothing throughout the entire experiment. Thus we classify him as a free rider. These results represent a statistically significant difference from random behavior. A chi-squared test comparing the actual categorization of subjects against a null hypothesis of equal probability of all three types, rejects the null at $\mathrm{p}<.01$.

This experiment demonstrates similar evidence in favor of theories of reciprocity as previous ones. In addition, however, we can use the data to compare between different types of reciprocity. This is done in the next subsection.

\section{Different Types of Reciprocity}

This data allows us to compare three different types of reciprocity: maximum, minimum and middle. In maximum reciprocity, subjects would attempt to match the maximum contribution of the other three members of their group. In minimum reciprocity, subjects would attempt to match the minimum contribution of the other three members of their group. Finally, in middle reciprocity, subjects would attempt to match the contributions of the middle contributor of the other three members of their group.

Our goal is to determine which of these three models of reciprocity best fits the data. That is, which of the minimum, maximum or middle contribution of an individual's partners better predicts an individual's own contribution. We estimate four random effect OLS 
regressions, as below

$\mathrm{CONT}_{\mathrm{it}}=\alpha_{0}+\alpha_{1} \mathrm{MIN}_{\mathrm{t}}+\alpha_{2} \mathrm{PERIOD}+\sum_{\mathrm{i} \neq 1} \beta_{\mathrm{i}} \mathrm{IND}+\varepsilon_{\mathrm{i}}$

$\mathrm{CONT}_{\mathrm{it}}=\alpha_{0}+\alpha_{1} \mathrm{MAX}_{\mathrm{t}}+\alpha_{2} \mathrm{PERIOD}+\sum_{\mathrm{i} \neq 1} \beta_{\mathrm{i}} \mathrm{IND}+\varepsilon_{\mathrm{i}}$

$\mathrm{CONT}_{\mathrm{it}}=\alpha_{0}+\alpha_{1} \mathrm{MID}_{\mathrm{t}}+\alpha_{2}$ PERIOD $+\sum_{\mathrm{i} \neq 1} \beta_{\mathrm{i}} \mathrm{IND}+\varepsilon_{\mathrm{i}}$

$\mathrm{CONT}_{\mathrm{it}}=\alpha_{0}+\alpha_{1} \mathrm{MIN}_{\mathrm{t}}+\alpha_{2} \mathrm{MAX}_{\mathrm{t}}+\alpha_{3} \mathrm{MID}_{\mathrm{t}}+\alpha_{4} \mathrm{PERIOD}+\sum_{\mathrm{i} \neq 1} \beta_{\mathrm{i}} \mathrm{IND}+\varepsilon_{\mathrm{i}}$

Results from these regressions are shown in Table 11.

Insert Table 11 about here

Evidence from these regressions suggests that middle reciprocity is a better predictor than either minimum or maximum reciprocity. First, in the individual regressions (1), (2) and (3), the t-statistic is higher for the middle contribution than for either of the others. In addition, in the regression which includes all measures (4), only middle is significantly different than zero. This suggests that the middle contribution of the others in a subject's group is a better predictor of that subject's own contribution than either the maximum or the minimum. In all of these regressions we observe a similar result as above of significantly positive contributions (positive intercept coefficient) which decrease over time (negative PERIOD coefficient) as in previous studies (Davis and Holt, 1994; Ledyard, 1995).

Another way to demonstrate this relationship is through a standardized regression.

Here, the same regression equations are run as above, except the independent measures (MIN, MAX and MID) are standardized to be distributed normally with mean zero and variance one. In these regressions, the absolute size of the coefficients can be compared directly. Results from the standardized random effects OLS regressions are shown in Table 12. 
Insert Table 12 about here

Again, we see that the middle contribution of the other players is a better predictor of a subject's own contribution than either the maximum or the minimum. The standardized coefficient on MID is higher than either of the other two, and in the final regression (4), only MID remains significantly different than zero. And again we observe significantly positive contributions (positive intercept coefficient) which decrease over time (negative PERIOD coefficient) as in previous studies (Davis and Holt, 1994; Ledyard, 1995).

\section{Conclusion}

This experiment sheds light on exactly what subjects in this experiment might be trying to reciprocate. First, our results are consistent with the comparative statics of reciprocity theories in yet another setting, this time where subjects are given information about the full distribution of their group's contributions, not just the total. Then, we test whether the minimum, maximum or middle contribution of the other three players is a better predictor of a subject's own contribution. We find significant evidence for middle reciprocity, suggesting that subjects try to match the median or average contributions of others, rather than the minimum (as suggested by Sugden's theory of reciprocity) or the maximum.

\section{Discussion and Conclusion}

The experiments reported in this paper tested comparative statics predictions of three models consistent with observations of voluntary public goods provision; commitment, altruism and reciprocity. The results support the reciprocity model in which individual contributions are positively related to the contributions of others, or to their beliefs about those 
contributions.

Reciprocal behavior is also supported by anecdotal evidence. Charities eliciting contributions often suggest a particular level as the "standard" gift or report the size of their "average" contribution. Presumably this influences individual's beliefs of what others are giving, thus causing them to give more.

Even the very wealthy seem to exhibit reciprocal behavior, in this example from Forbes Magazine, "Seattle's Lakeside Upper School counts ... Bill Gates among its alumni. Rumor has it a fundraiser for the high school put the bite on Gates, who asked: 'How much is everyone else giving?' About $\$ 75$ he was told. 'So put me down for \$75,' said Gates.” (January 22, 1996, p. 18).

While middle-matching behavior like this is consistent with the reciprocity principle, it may be adaptively rational as well. Societies whose members follow this principle are more likely to be able to supply public goods than societies whose members practice self-interest utility maximization. One can also imagine an individually rational reason to behave reciprocally. If the quality or reliability of charitable groups are not known, individual contributors may use the contributions of others as a signal for how much they should contribute themselves (as in Vesterlund, 1998).

This study examines the factors that motivate individuals to make voluntary contributions in social dilemma situations. In particular, it finds support for reciprocity theories over commitment theories, altruistic theories and traditional free-riding theories. We find a significant and positive relationship between an individual's contribution and his belief about the contributions of others in his group, as well as between an individual's contribution and the actual contributions of the others in his group. These results suggest that players act 
as though part of their objective is to match the contributions of other members. 


\section{References}

Abbink, Klaus, Bernd Irlenbusch and Elke Renner (1997). "The Moonlighting Game: An Experimental Study on Reciprocity and Retribution." Discussion Paper B-415, University of Bonn.

Abel, Andrew and Mark Warshawsky (1988). " "Specification of the Joy of Giving: Insights from Altruism." Review of Economics and Statistics, vol 70, pp. 145-149.

Abrams, Burton and Mark Schitz (1978). "The Crowding Out Effect of Governmental Transfers on Private Charitable Contributions.” Public Choice, vol 33, pp. 29-39.

Abrams, Burton and Mark Schitz (1984). "The Crowding Out Effect of Governmental Transfers on Private Charitable Contributions: Cross Sectional Evidence." National Tax Journal, vol 37, pp. 563-568.

Akerlof, George (1982). "Labor Contracts as Partial Gift Exchange." Quarterly Journal of Economics, vol 97, pp. 543-569.

Akerlof, George (1984). "Gift Exchange and Efficiency-Wage Theory: Four Views." American Economic Review, vol 74, pp. 79-83.

Altonji, Joseph, Fumio Hayashi and Laurence Kotlikoff (1992). Is the Extended Family Altruistically Linked? Direct Tests Using Micro Data.” American Economic Review, vol 82, pp. 1177-1198.

Andreoni, James (1988a). "Privately Provided Public Goods in a Large Economy: The Limits of Altruism." Journal of Public Economics, vol 35, pp. 57-73.

Andreoni, James (1988b). "Why Free Ride? Strategies and Learning in Public Goods Experiments." Journal of Public Economics, vol 37, pp. 291-304.

Andreoni, James (1989). "Giving with Impure Altruism: Applications to Charity and Ricardian Equivalence." Journal of Political Economy, vol 97, pp. 1447-1458.

Andreoni, James (1990). "Impure Altruism and Donations to Public Goods: A Theory of Warm-Glow Giving." Economic Journal, vol 100, pp. 464-477.

Andreoni, James (1993). "An Experimental Test of the Public Goods Crowding-Out Hypothesis.” American Economic Review, vol 83, pp. 1317-1327.

Andreoni, James (1995). "Cooperation in Public-Goods Experiments: Kindness or Confusion?” American Economic Review, vol 85, pp. 891-904.

Andreoni, James and John Miller (1993). "Rational Cooperation in the Finitely Repeated 
Prisoner's Dilemma: Experimental Evidence.” Economic Journal, vol 103, pp. 570-585.

Andreoni, James and Lise Vesterlund (1997). "Which is the Fair Sex? Gender Differences in Altruism.” Working Paper, University of Wisconsin

Arrow, Kenneth (1975 ). "Gifts and Exchanges." in Altruism, Morality and Economic Theory, E.S. Phelps, ed. New York, NY: Russell Sage Foundation.

Asch, Peter, Gary Gigliotti and James Polito (1993). "Free Riding with Discrete and Continuous Public Goods: Some Experimental Evidence.” Public Choice, vol 77, pp. 293-305.

Baron, Jon and Mark Spranca (1997). "Protected Values." Organizational Behavior and Human Decision Processes, vol 70, pp. 1-16.

Baldry, Jonathan (1987). "Income Tax Evasion and the Tax Schedule." Public Finance, vol 42, pp. 357-383.

Becker, Gary (1974). “A Theory of Social Interaction.” Journal of Political Economy, vol 82, pp. 1063-1093.

Becker, Gary and Robert Barro (1988). "A Reformulation of the Economic Theory of Fertility.” Quarterly Journal of Economics, vol 103, pp. 1-25.

Berg, Joyce, John Dickhaut and Kevin McCabe (1995). " "Trust, Reciprocity and Social History." Games and Economic Behavior, vol 10, pp. 122-142.

Bergstrom, Theodore (1995). "On the Evolution of Altruistic Ethical Rules for Siblings." American Economic Review, vol 85, pp. 58-81.

Bergstrom, Theodore and Oded Stark (1993). "How Altruism Can Prevail in an Evolutionary Environment." American Economic Review, vol 83, pp. 149-155.

Bernheim, Douglas (1986). " "On the Voluntary and Involuntary Provision of Public Goods." American Economic Review, vol 76, ppp. 789-793.

Bernheim, Douglas and Oded Stark (1988). "Altruism within the Family Reconsidered: Do Nice Guys Finish Last?” American Economic Review, vol 78, pp. 1034-1045.

Bolton, Gary, Jordi Brandts and Elena Katok (1996). "A Simple Test of Explanations for Contributions in Social Dilemmas.” Working Paper, Pennsylvania State University.

Bolton, Gary, Jordi Brandts and Axel Ockenfels (1997). Measuring Motivations for the Reciprocal Responses Observed in a Simple Dilemma Game.” Working Paper, Pennsylvania State University. 
Bolton, Gary and Elena Katok (1995). "An Experimental Test for Gender Differences in Beneficent Behavior.” Economics Letters, vol 48, pp. 287-292.

Bordignon, Massimo (1990). "Was Kant Right? Voluntary Provision of Public Goods under the Principle of Unconditional Commitment.” Economic Notes, vol 0, pp. 342-372.

Bordignon, Massimo (1993). “A Fairness Approach to Income-Tax Evasion.” Journal of Public Economics, vol 52, pp. 345-362.

Bosco, Luigi and Luigi Mittone (1997). "Tax Evasion and Moral Constraints: Some Experimental Evidence.” Kyklos, vol 50, pp. 297-324.

Brown-Kruse, Jamie and David Hummels (1993). "Gender Effects in Laboratory Public-Goods Contribution: Do Individuals Put Their Money Where Their Mouth Is? Journal of Economic Behavior and Organization, vol 22, pp. 255-267.

Buchan, Nancy, Eric Johnson and Rachel Croson (1998). "The Cultural Boundaries of Trust and Reciprocity in Economic Bargaining." OPIM Working Paper, The Wharton School of the University of Pennsylvania.

Burlando, R. and John Hey (1997). "Do Anglo-Saxons Free Ride More?” Journal of Public Economics, vol 64, pp. 41-60.

Camerer, Colin and Richard Thaler (1995). "Ultimatums, Dictators and Manners." Journal of Economic Perspectives, vol 9, pp. 209-219.

Chakrabarti, Subir, William Lord and Peter Rangazas (1993). "Uncertain Altruism and Investment in Children." American Economic Review, vol 83, pp. 994-1002.

Clotfelter, C. (1985). Federal Tax Policy and Charitable Giving. Chicago, IL: University of Chicago Press.

Coate, Stephen (1995). “Altruism, the Samaritan’s Dilemma, and Government Transfer Policy." American Economic Review, vol 85, pp. 46-57.

Collard, David (1978). Altruism and Economy. Oxford: Martin Robertson.

Collard, David (1983). "Economics of Philanthropy: A Comment." Economic Journal, vol 93, pp. 637-638

Cooper, Russell, Douglas DeJong, Robert Forsythe and Thomas Ross (1996). "Cooperation without Reputation: Experimental Evidence from Prisoners' Dilemma Games." Games and Economic Behavior, vol 12, pp. 187-218.

Cornes, Richard and Todd Sandler (1984). "The Theory of Public Goods: Non-Nash Behaviour." Journal of Public Economics, vol 23, pp. 367-379. 
Cox, Donald (1987). "Motives for Private Income Transfers." Journal of Political Economy, vol 95, pp. 508-546.

Cox, Donald and Mark Rank (1992). " Inter-vivos Transfers and Intergenerational Exchange." Review of Economics and Statistics, vol 74, pp. 305-314.

Croson, Rachel (1996). "Partners and Strangers Revisited." Economics Letters, vol 53, pp. 25-32.

Croson, Rachel (1997). "Effects of Eliciting Beliefs in a Linear Public Goods Game." OPIM Working Paper, The Wharton School of the University of Pennsylvania.

Croson, Rachel (forthcoming). Feedback in Voluntary Contribution Mechanisms: An Experiment in Team Production. Research in Experimental Economics.

Davis, Douglas and Charles Holt (1994). Experimental Economics. Princeton, NJ: Princeton University Press.

Dudley, Dean (1993). "Individual Provision Choices in Voluntary Contribution Public Goods Environments: An Experimental Approach.” PhD thesis from Indiana University.

Eckel, Catherine and Philip Grossman (1996a). "The Relative Price of Fairness: Gender Differences in a Punishment Game." Journal of Economic Behavior and Organization, vol 30, pp. 143-158.

Eckel, Catherine and Philip Grossman (1996b). “Altruism in Anonymous Dictator Games." Games and Economic Behavior, vol 16, pp. 181-191.

--- (1996). Forbes. Jan 22, v157, \#2, p. 18. In Forbes Informer, edited by Kate Bohner Lewis.

Fehr, Ernst and Simon Gachter (forthcoming). "Reciprocity and Economics: The Economic Implications of Homo Reciprocans." Forthcoming, European Economic Review.

Fehr, Ernst, Simon Gachter and Georg Kirchsteiger (1997). "Reciprocity as a Contract Enforcement Device: Experimental Evidence.” Econometrica, vol 65, pp. 833-860.

Fehr, Ernst, Georg Kirchsteiger and Arno Riedl (1993). "Does Fairness Prevent Market Clearing?: An Experimental Investigation." Quarterly Journal of Economics, vol 108, pp. 437-459.

Fehr, Ernst, Georg Kirchsteiger and Arno Riedl (1996). "Involuntary Unemployment and Non-compensating Wage Differentials in an Experimental Labor Market." Economic Journal, vol 106, pp. 106-121. 
Fehr, Ernst, Georg Kirchsteiger and Arno Riedl (1998). "Gift Exchange and Reciprocity in Competitive Experimental Markets.” European Economic Review, vol 42, pp. 1-34.

Fehr, Ernst and Elena Tougareva (1996). "Do High Monetary Stakes Remove Reciprocal Fairness?: Experimental Evidence from Russia.” Working Paper, University of Zurich.

Fehr, Ernst and Jean-Robert Tyran (1996). "How do Institutions and Fairness Interact?" Central European Journal for Operations Research and Economics, vol 4, pp. 69-84.

Feldstein, M. (1975). “The Income Tax and Charitable Contirbuitons: Part II--The Impact on Religious, Educational and Other Organizations." National Tax Journal, vol 28, pp. 81-100.

Fleishman, John (1988). "The Effects of Decision Framing and Others' Behavior on Cooperation in a Social Dilemma." Journal of Conflict Resolution, vol 32, pp. 162-180.

Forsythe, Robert, John Kennan and Barry Sopher (1991). “An Experimental Analysis of Strikes in Bargaining Games with One-Sided Private Information." American Economic Review, vol 81, pp. 253-278.

Forsythe, Robert, Joel Horowitz, Nathan Savin and Martin Sefton (1994). "Fairness in Simple Bargaining Experiments.” Games and Economic Behavior, vol 6, pp. 347-369.

Frank, Richard and David Salkever (1991). " "The Supply of Charity Services by Nonprofit Hospitals: Motives and Market Structure.” Rand Journal of Economics, vol 22, pp. 430-445.

Frey, Bruno (1993). "Shirking or Work Morale? The Impact of Regulating." European Economic Review, vol 37, pp. 1523-1532.

Gachter, Simon and Armin Falk (1997). "Reputation or Reciprocity?” Working Paper, University of Zurich.

Gibbard, Allan and William Harper (1988). "Counterfactuals and Two Kinds of Expected Utility." in Decision, Probability and Utility: Selected Readings, Gardenfors and Sahlin (eds.), New York, NY: Cambridge University Press.

--- (1996). Giving USA, Kaplan, Ann E. (ed.) New York, NY: American Association of Funding Counsel.

Greene, William (1990). Econometric Analysis. New York, NY: Macmillan Publishing Company.

Guth, Werner, Peter Ockenfels and Markus Wendel (1997). "Cooperation Based on Trust: An Experimental Investigation.” Journal of Economic Psychology, vol 18, pp. 15-43.

Haltiwanger, John and Michael Waldman (1993). "The Role of Altruism in Economic Interaction.” Journal of Economic Behavior and Organization, vol 21, pp. 1-15. 
Harsanyi, John (1980). "Rule Utilitarianism, Rights, Obligations and the Theory of Rational Behaviour." Theory and Decision, vol 12, pp. 115-133.

Hayashi, Fumio (1995). "Is the Japanese Extended Family Altruistically Linked? A Test Based on Engel Curves." Journal of Political Economy, vol 103, pp. 661-674.

Hoffman, Elizabeth, Kevin McCabe and Vernon Smith (1996). "Social Distance and Other-Regarding Behavior in Dictator Games." American Economic Review, vol 86, pp. 653-660.

Hoffman, Elizabeth, Kevin McCabe, Jason Shachat and Vernon Smith (1994). "Preferences, Property-Rights and Anonymity in Bargaining Games." Games and Economic Behavior, vol 7, pp. 346-380.

Hollander, Heinz (1990). "A Social Exchange Approach to Voluntary Contribution." American Economic Review, vol 80, pp. 1157-1167.

Hood, R., S. Martin and Lars Osberg (1977). "Economic Determinants of Individual Charitable Donations in Canada." Canadian Journal of Economics, vol 10, pp. 653-669.

Hori, Hajime (1992). "Utility Functionals with Nonpaternalistic Intergenerational Altruism: The Case Where Altruism Extends to Many Generations." Journal of Economic Theory, vol 56, pp. 451-467.

Isaac, R. Mark and James Walker (1988a). "Group Size Effects in Public Goods Provision: The Voluntary Contribution Mechanism.” Quarterly Journal of Economics, vol 103, pp. 179-199.

Isaac, R. Mark and James Walker (1988b). "Communication and Free-Riding Behavior: The Voluntary Contribution Mechanism.” Economic Inquiry, vol 26, pp. 585-608.

Isaac, R. Mark and James Walker (1991). "Costly Communication: An Experiment in a Nested Public Goods Problem.” in Laboratory Research in Political Economy, Palfrey (ed.), Ann Arbor, MI: University of Michigan Press.

Isaac, R. Mark and James Walker (1992). "Nash as an Organizing Principle in the Voluntary Contribution of Public Goods.” Working Paper, Indiana University.

Isaac, R. Mark, James Walker and Arlington Williams (1994). "Group Size and the Voluntary Provision of Public Goods: Experimental Evidence Using Large Groups.” Journal of Public Economics, vol 54, pp. 1-36.

Jacobsen, Eva and Abdolkarim Sadrieh (1996). "Experimental Proof for the Motivational Importance of Reciprocity.” Discussion Paper B-386, University of Bonn. 
Jones, Philip (1996). "Rents from In-Kind Subsidy: "Charity" in the Public Sector." Public Choice, vol 86, pp. 359-378.

Jones-Lee, Michael. (1992). "Paternalistic Altruism and the Value of Statistical Life." Economic Journal, vol 102, pp. 80-90.

Khanna, Jyoti, John Posnett and Todd Sandler (1995). "Charity Donations in the UK: New Evidence Based on Panel Data.” Journal of Public Economics, vol 56, pp. 257-272.

Kirchler, Erich, Ernst Fehr and Robert Evans (1996). "Social Exchange in the Labor Market: Reciprocity and Trust versus Egoistic Money Maximization.” Journal of Economic Psychology, vol 17, pp. 313-341.

Kogut, Bruce (1989). "The Stability of Joint Ventures: Reciprocity and Competitive Rivalry.” Journal of Industrial Economics, vol 38, pp. 183-198.

Kranton, Rachel (1996). " "Reciprocal Exchange: A Self-Sustaining System.” American Economic Review, vol 86, pp. 830-851.

Kreps, David, Paul Milgrom, John Roberts and Robert Wilson (1982). "Rational Cooperation in the Finitely Repeated Prisoners' Dilemma." Journal of Economic Theory, vol 27, pp. 245-252.

Laffont, Jean-Jacques (1975). "Macroeconomic Constraints, Economic Efficiency and Ethics: An Introduction to Kantian Economics." Economica , vol. 42, pp. 430-437.

Laitner, John and F. Thomas Juster (1996). "New Evidence on Altruism: A Study of TIAA-CREF Retirees.” American Economic Review, vol 86, pp. 893-908.

Ledyard, John (1995). "Public Goods: A Survey of Experimental Research." in The Handbook of Experimental Economics. Roth and Kagel, eds. Princeton, NJ: Princeton University Press.

Lewis, David (1988). "Causal Decision Theory.” in Decision, Probability and Utility: Selected Readings, Gardenfors and Sahlin (eds.), New York, NY: Cambridge University Press.

Margolis, Howard (1982). Selfishness, Altruism and Rationality. Cambridge: Cambridge University Press.

Marwell, Gerald and Ruth Ames (1979). "Experiments on the Provision of Public Goods I: Resources, Interest, Group Size and the Free-Rider Problem." American Journal of Sociology, vol 84, pp. 1335-1360..

Marwell, Gerald and Ruth Ames (1980). "Experiments on the Provision of Public Goods II: Provision Points, Stakes, Experience, and the Free Rider Problem.” American Journal of Sociology, vol 85, pp. 926-937. 
Marwell, Gerald and Ruth Ames (1981). "Economists Free Ride, Does Anyone Else?: Experiments on the Provision of Public Goods, IV." Journal of Public Economics, vol 15, pp. 295-310.

Messick, David, Henk Wilke, Marilynn Brewer, Roderick Kramer, Patricia English Zemke and Layton Lui (1983). "Individual Adaptations and Structural Change as Solutions to Social Dilemmas." Journal of Personality and Social Psychology, vol 44, pp. 294-309.

--- (1998). “Our Titanic Love Affair.” Newsweek, February 23, p. 58 by David Anson.

Nozick, Robert (1990). "Newcomb's Problem and Two Principles of Choice." in Rationality in Action: Contemporary Approaches, Moser (ed.), New York, NY: Cambridge University Press.

Offerman, Theo, Joep Sonnemans and Arthur Schram (1996). "Value Orientations, Expectations and Voluntary Contributions in Public Goods.” Economic Journal, vol 106, pp. 817-845.

Palfrey, Thomas and Jeffrey Prisbrey (1996). "Altruism, Reputation and Noise in Linear Public Goods Experiments.” Journal of Public Economics, vol 61, pp. 409-427.

Palfrey, Thomas and Howard Rosenthal (1988). "Private Incentives in Social Dilemmas: The Effects of Incomplete Information and Altruism." Journal of Public Economics, vol 35, pp. 309-332.

Poppe, Matthijs and Lisbeth Utens (1986). "Effects of Greed and Fear of being Gypped in a Social Dilemma Situation with Changing Pool Size." Journal of Economic Psychology, Vol 7, pp. 61-73.

Posnett, John and Todd Sandler (1986). " "Joint Supply and the Finance of Charitable Activity." Public Finance Quarterly, vol 14, pp. 209-222.

Rangazas, Peter (1991). "Human Capital Investment in Wealth-Constrained Families with Two-Sided Altruism.” Economics Letters, vol 35, pp. 137-141.

Rapoport, Amnon and Dalit Eshed-Levy (1989). " "Provision of step-level public goods: Effects of greed and fear of being gypped." Organizational Behavior and Human Decision Processes, vol 44, pp. 325-344.

Rapoport, Amnon and Ramzi Suleiman (1993). "Incremental contribution in step-level public goods games with asymmetric players." Organizational Behavior and Human Decision Processes, vol 55, pp. 171-194.

Roberts, Russell (1984). “A Positive Model of Private Charity and Public Transfers” Journal of Political Economy, vol 92, pp. 136-148. 
Roberts, Russell (1987). "Financing Public Goods.” Journal of Political Economy, vol 95, pp. 420-437.

Rotemberg, Julio (1994). "Human Relations in the Workplace." Journal of Political Economy, vol 102, pp. 684-717.

Saijo, Toshi and H. Nakamura (1995). " "The Spite Dilemma in Voluntary Contribution Mechanism Experiments.” Journal of Conflict Resolution, vol 39, pp. 535-560.

Samuelson, Paul (1993). "Altruism as a Problem Involving Group versus Individual Selection in Economics and Biology." American Economic Review, vol 83, pp. 143-148.

Schroeder, David, Thomas Jensen, Andrew Reed, Debra Sullivan and Michael Schwab (1983). "The Actions of Others as Determinants of Behavior in Social Trap Situations." Journal of Experimental Social Psychology, vol 19, pp. 522-539.

Schwartz, Robert (1970). "Personal Philanthropic Contributions.” Journal of Political Economy, vol 78, pp. 1264-1291.

Sefton, Martin and Richard Steinberg (1996). "Reward Structures in Public Goods Experiments." Journal of Public Economics, vol 61, pp. 263-287.

Sell, Jane and Rick Wilson (1991). "Levels of Information and Contributions to Public Goods." Social Forces, vol 70, pp. 107-124.

Sen, Amartya (1977). "Rational Fools: A Critique of the Behavioral Foundations of Economic Theory." Journal of Philosophy and Public Affairs, vol 6, pp. 317-344.

Shafir, Eldar and Amos Tversky (1992). "Thinking Through Uncertainty: Nonconsequential Reasoning and Choice." Cognitive Psychology, vol 24, pp. 449-474.

Smith, Vernon (1990). Experimental Economics: Behavioral Lessons for Microeconomic Theory and Applications." Nancy L. Schwartz Memorial Lecture. Evanston, IL:

Northwestern University, Kellogg Graduate School of Management.

Smith, Vincent, Michael Kehoe and Mary Cremer (1995). "The Private Provision of Public Goods: Altruism and Voluntary Giving.” Journal of Public Economics, vol 58, pp. 107-126.

Solow, John (1994). " "Paternalistic Preferences, Interpersonal Transfers and Reciprocity." Southern Economic Journal, vol. 61, pp. 379-386.

Stigler, George (1974). "Free Riders and Collective Action: An Appendix to Theories of Economic Regulation.” Bell Journal of Economics, vol 5, pp. 359-365.

Strawcyznski, Michel (1994). “Government Intervention as a Bequest Substitute.” Journal of 
Public Economics, vol 53, pp. 477-495.

Struthers, John and Alistair Young (1989). "The Economics of Voting: Theories and Evidence." Journal of Economic Studies, vol 16, pp. 1-43.

Sugden, Robert (1984). "Reciprocity: The Supply of Public Goods through Voluntary Contributions.” Economic Journal, vol 94, pp. 772-787.

Sugden, Robert (1985). "Consistent Conjectures and Voluntary Contributions to Public Goods: Why the Conventional Theory Does not Work." Journal of Public Economics, vol 27, pp. 117-124.

Suleiman, Ramzi and Amnon Rapoport (1992). "Provision of Step-level Public Goods with Continuous Contribution.” Journal of Behavioral Decision Making, vol 5, pp. 133-153.

Tamura, Robert (1994). "Fertility, Human Capital and the Wealth of Families." Economic Theory, vol 4, pp. 593-603.

Tcha, MoonJoong (1995). "Altruism, Household Size and Migration.” Economics Letters, vol 49, pp. 441-445.

Tversky, Amos and Eldar Shafir (1992). "The Disjunction Effect in Choice Under Uncertainty." Psychological Science, vol 3, pp. 305-309.

Unger, Lynette (1991). "Altruism as a Motivation to Volunteer." Journal of Economic Psychology, vol 12, pp. 71-100.

Van Huyck, John, Raymond Battalio and M Walters (1995). "Commitment versus Discretion in the Peasant-Dictator Game.” Games and Economic Behavior, vol 10, pp. 143-170.

van Winden, Frans and Claudia Keser (1997). "Partners Contribute More to Public Goods than Strangers: Conditional Cooperation.” Working Paper, University of Amsterdam.

Vesterlund, Lise (1998). “The Informational Value of Sequential Fundraising.” Working Paper, Iowa State University.

Wade-Benzoni, Kimberly, Ann Tenbrunsel and Max Bazerman (1996). "Egocentric Interpretations of Fairness in Asymmetric, Environmental Social Dilemmas: Explaining Harvesting Behavior and the Role of Communication." Organizational Behavior and Human Decision Processes, vol 67, pp. 111-126.

Warr, Peter (1982). "Pareto Optimal Redistribution and Private Charity." Journal of Public Economics, vol 18, pp. 131-138.

Warr, Peter (1983). "The Private Provision of a Public Good is Independent of the Distribution of Income." Economics Letters, vol 13, pp. 207-211. 
Weimann, Joachim (1994). "Individual Behaviour in a Free Riding Experiment" Journal of Public Economics, vol 54, pp. 185-200.

Wilhelm, Mark (1996). "Bequest Behavior and the Effect of Heirs Earnings: Testing the Altruistic Model of Bequests.” American Economic Review, vol 86, pp. 874-892.

Wilson, Rick and Jane Sell (1997). "Liar, Liar: Cheap Talk and Reputation in Repeated Public Goods Settings.” Journal of Conflict Resolution, vol 41, pp. 695-717. 















\section{Footnotes}

The actual amount contributed by individuals in 1995 was $\$ 116,230,000,000$. This number excludes charitable giving by corporations, foundations and bequests.

That is, multiple agents can consume the good at the same time (nonrival) and it is not possible to exclude agents who did not pay for the good from consuming it (nonexcludable).

The multiple $\mathrm{P}$ is often called the marginal per capita return (MPCR) and is the marginal return to each individual on a contribution of one unit to the group account (Isaac and Walker, 1988a).

Other studies using this mechanism have examined the effect of relative payoffs (Isaac and Walker, 1988a) communication (Isaac and Walker, 1988b, 1991; Wilson and Sell, 1997), culture (Burlando and Hey, 1997), reputation and learning (Andreoni, 1988b; Weimann, 1994; Croson, 1996; van Winden and Keser, 1997), random noise (Andreoni, 1995; Palfrey and Prisbrey, 1996), payments (Sefton and Steinberg, 1996), spite (Saijo and Nakamura, 1995), group size (Isaac, Walker and Williams, 1994), discreteness of the public good (Asch, Gigliotti and Polito, 1993), and information (Sell and Wilson, 1991; Croson, forthcoming), as well as many other issues.

A similar technique of belief elicitation has been used in public goods games in a slightly different context. In these studies, voluntary contribution mechanisms are run which have interior Nash equilibria (rather than a boundary equilibrium). Authors then elicit subjects' beliefs about others' behavior and categorizes subjects based on whether they play best responses to their own beliefs (see e.g. Isaac and Walker, 1992; Dudley 1993; Offerman, Sonnemans and Schram, 1996; Suleiman and Rapoport, 1992; Rapoport and Eshed-Levy, 1989; Rapoport and Suleiman, 1993; ).

More recent work in philosophy (e.g. Gibbard and Harper, 1988; Lewis, 1988; Nozick, 1990) and psychology (e.g. nonconsequential reasoning of Shafir and Tversky, 1993 and Tversky and Shafir, 1992) suggests that these sorts of misperceptions of causality both can be and are used to solve many social and individual decision problems.

Laffont (1975) also discusses the social benefits of a government convincing the population that 
this belief is true.

In fact, in this linear case, $\mathrm{Xi}^{*}=\mathrm{E}_{\mathrm{i}}$,

Both Collard (1978) and Becker (1974) show that altruism need not lead to an infinite explosion of utility between multiple altruistic individuals as long as an individual's own utility (or consumption) is more important to him than anothers'.

That is, each dollar increase in government grants should result in a dollar decrease in private giving.

A number of interesting experimental studies have investigated gender differences in altruistic preferences with different results. Bolton and Katok (1995) showed no significant differences while other studies (Andreoni and Vesterlund, 1997; Eckel and Grossman, 1996a; Brown-Kruse and Hummels, 1993) demonstrate significant differences.

Other theories of altruism also predict this negative correlation (e.g. Arrow, 1975; Sen, 1977; Roberts, 1984, 1987; Posnett and Sandler, 1986; Margolis, 1982; Schwartz, 1970; Hood, Martin and Osberg, 1977; Collard, 1978).

It is worth noting that such a positive correlation has been assumed in theories of voluntary activities (e.g. Cornes and Sandler, 1984).

Because they estimated the contributions of the other three members of the group, subjects could not influence the accuracy of their guess by strategically changing their own contribution.

In addition to their earnings from the public good, subjects earned $50 \phi$ if their estimate was exactly right. If their estimate was a bit off, they earned $25 \varnothing$ divided by the (absolute) distance between their estimate and the true contribution. This payment scheme leads to an approximation of a single-peaked curve.

Croson (1997) compares contributing behavior between this treatment and a traditional linear public goods experiment treatment.

In addition there were three practice periods before the first game began to familiarize subjects with the computer program and the process. Subjects were not paid their earnings during the practice periods and no practice periods were run before the second game. Raw data as well as the instructions used are available from the author.

The same regression including dummy variables for each group had similar results, as did one including dummies for the period numbers and a two-factor random effects regression (individual and period).

Notice we have two observations for each individual, one for period 1 of the original game and one for period 1 of the restart game. Thus we include the individual dummies and random effects. 
Identical regressions without the individual dummy variables yield similar results (the period 1 coefficient on GUESS is .192, $\mathrm{p}<.01$, the period 10 coefficient on GUESS is .184, $\mathrm{p}<.01$ ). Identical regressions run for each of the games separately on period 1 play also yield similar results (for the original game, the period 1 coefficient on GUESS is $.215, \mathrm{p}<.01$ and for the restart game, the same coefficient is $.313, \mathrm{p}<.01)$.

A similar test excluding the observations of zero correlation was also run. The null hypothesis of equal number of positive and negative correlations was rejected at $p<.01$.

The hypothesis that the mean of the distribution of errors in the first game is equal to zero can be rejected using a t-test at the 5\% level for eight out of 24 subjects. It cannot be rejected for any subjects in the second game.

A similar test excluding the observations of zero contributions was also run. The null hypothesis of equal number of positive and negative correlations was rejected at $\mathrm{p}<.01$ for all four treatments as well as the combined data.

Remember that Sugden's notion of reciprocity is a simultaneous rather than a sequential one. It's not that subjects in this experiment are "rewarding" their group members for past performance. Instead, they are trying to "match" the contributions they expect of others in their group.

Notice it is quite possible for an individual's contribution to be above the maximum (or below the minimum) of the other three members of his group. In fact, the contributions one person in each group in each period will have this characteristic.

A more recent example of reciprocal behavior is found in the entertainment industry. During the making of Titanic, when the film was running over budget and failed to make the planned release date, director James Cameron voluntarily gave up fees for the film as well as his percentage of the profits in order to assuage concerns of executives at Twentieth Century Fox and Paramount Picture Studios. Now that Titanic is the third-biggest grossing film of all time, those waived fees and percentages total to approximately $\$ 50$ million. A report in Newsweek (1998) says that studio heads are now considering voluntarily and unilaterally paying Cameron the very fees he had agreed to waive. 